\title{
Development of evaluation indicators in psychosocial projects: balance between a creative challenge and research rigor
}

\section{Dean Ajdukovic}

Evaluation of psychosocial and community oriented projects includes a series of procedures to determine if project outcomes are achieved by an activity planned to help reach an individual or socially relevant goal. Typically, various stakeholders have an interest in evaluation of psychosocial projects. These may include project staff and manager, donors, authorities, beneficiaries and the community. Sometimes their interest in evaluation seems to be in conflict, but clarification of interests can lead to complementary positions. Evaluation is basically a decision making tool about the future of a project. The basic assumption in evaluation is that it should identify observable or measurable outcomes (consequences, results) that can be used to demonstrate that the project is reaching the goal and objectives. One of the crucial elements in this process are evaluation indicators which need to satisfy several universal criteria, while their specific content and data collection method should reflect the specifics of the project under evaluation.

Keywords: evaluation, criteria, indicators

\section{The thinking behind evaluation}

Psychosocial work attempts to affect people's lives in a positive way, either by alleviating the detrimental conditions of their life, relieving suffering or improving the quality of their life in other ways. It includes various interventions and processes provided by both professional and paraprofessional care providers. These interventions may require different levels of professional expertise. Typically, the assistance requiring more expertise is needed by fewer community members, while less sophisticated interventions can be provided by more diverse groups of care providers, including: youth leaders, community workers, spiritual leaders, adhoc volunteer groups, neighbourhood self help groups and similar resources. Psychosocial work can be viewed as a process of empowering the individual, family, groups and communities to recover from conditions negatively affecting their life, without harm to themselves or others (Ajdukovic, 1995).

The organisational framework for carrying out community psychosocial work is typically a time limited project with defined objectives, target populations and beneficiary groups, description of activities, project staff and resources. Whether it is a volunteer action to organise delivery of groceries to the elderly neighbours, setting up a temporary community counselling centre for traumatised individuals after a fire disaster, or a school based project helping to decrease tensions in an ethnically divided community, the single common feature is that resources must be mobilised at a given time and place. In other words, staff time (such as counsellors, community workers, legal advisors), 
materials (medicines, building materials, toys, food), transportation, office space, money and other resources must be available to run a specific psychosocial project as planned. As the resources are always limited, this inevitably raises the question of effective use of resources in relation to the achievement of project objectives. In turn, this is related to various decisions about the project itself; should it be continued or terminated, should it be expanded to other locations, did the project generate important new knowledge to be used elsewhere. This is exactly why evaluation is important. Moreover, requests for well planned and relevant evaluations are becoming a standard in developing project proposals. Project evaluation is also directly related to demands for increasing accountability regarding resources mobilised for project implementation, for better costs effectiveness and clarity about achieving declared goals and objectives.

Project evaluation is an organised way of collecting data about a project that provides a base for making decisions. These decisions are not limited to the financial aspect of the project, but also to issues such as: have the needs been met; are there newly emerging needs that should be addressed; should the project be replicated at other locations; what have we learned from the project. Evaluation focuses on the relation between the project objectives and the achieved outcomes, and provides recommendations for future work. The fundamental assumption in evaluation is that project interventions should yield observable or measurable outcomes (consequences, results) that can be used to demonstrate that the project is reaching the goal and objectives. These outcomes are measured as evaluation indicators that are specific for each and every project. Evaluation indicators can be very different, they can indicate outcomes at a very concrete or a more abstract level, but a project cannot be evaluated unless there are one or more well described indicators, logically and empirically related to the project objectives and the overall goal (aim). The purpose of the present paper is to discuss issues of developing indicators in community oriented project evaluations.

\section{Types of evaluation, information gathering and evaluation indicators}

Two seemingly similar processes that are both related to project implementation could be confused: project monitoring and project evaluation. The confusion results from the fact that, in both cases, information is collected about what is being done in the project, but for different purposes.

In projectmonitoring the information about the type and frequency of activities, beneficiaries, effective use of time, resources and personnel are of primary interest. Such information is used for project management purposes and to document how the project is managing resources, providing activities, reaching the beneficiaries, etc., as it evolves. On the other hand, in project evaluation the gathering of information focuses on substantiating the relation between different inputs and achieving the project goal and objectives, and then formulating recommendations as a result of assessment of this relationship. However, data collected for monitoring purposes can serve as a valuable source of information in evaluation.

This paper differentiates three types of evaluation: firstly, evaluation of the need for a project; secondly, project process (formative) evaluation; and thirdly outcome (summation) evaluation. These three types are intrinsically related, and follow one from another. Some evaluation indicators can be used in all three of them, while in some, other 
indicators are specific for each type of evaluation.

Evaluation of the need for a project. This type of evaluation is based primarily on the assessment of needs, but is also more than that. It should be a part of the project planning process, and should be done before the project starts. This type of evaluation should answer questions like the ones listed below.

- Is there a problem or a need in a community?

- Who wants this problem to be addressed?

- How can this problem be addressed?

- Does the community want this need to be addressed in a specific way?

- Can the project be implemented in the way that will alleviate the problem or a need?

In order to answer these questions, indicators to assess the urgency of a problem or a need in a community are necessary. It can be based on statistical data about the prevalence of the problem or a need, related costs, informed opinions from people with a need (potential beneficiaries), authorities, community leaders and other local informants, data about public concern, etc. In addition, comparisons with the frequency of the problem in other communities, experiences with similar projects in other communities, required and available resources, available staff and other logistical issues are evaluated. The evaluation of need for a project should help make the first decision with regard to the project: is the project needed?

Indicators used in this type of evaluation may serve to establish the base line data against which achieved changes may be compared at a later stage, during the evaluation of outcomes.
Formative or process evaluation. The second type of evaluation serves as a decision tool for project implementation. This type of evaluation should answer questions like the ones listed below.

- Is the project implemented as planned?

- Is the project moving towards the objectives?

- Can the project be improved to increase its effectiveness?

Formative evaluation is usually done halfway through the project life. Indicators to assess project progress may include: data about type and extent of services provided by the project; who are the people receiving services and do they belong to the target group; how many are benefiting; are some changes in the life of beneficiaries observable, etc. At this point in time, the evaluation will also consider unforeseen circumstances in project implementation that may be related to the achievements of objectives. It will typically include recommendations for further project implementation, such as adjustments in project activities, access to beneficiaries or utilisation of resources. Information for process evaluation indicators can be sought from project staff and management, project beneficiaries and other people associated with beneficiaries who can provide information on the changes they may observe. Project documentation gathered within the regular monitoring, such as minutes and $\log$ of activities, can be useful sources of information for formative evaluation. Internal guidelines, treatment protocols, and procedures can also be very helpful in evaluating the progress of the project towards the goal and objectives.

Evaluation of outcomes. This type of evaluation is results oriented, looking for evidence 
indicating whether the project goal and objectives have been achieved. It is done at the completion of the project, hence also called summation evaluation. The key questions it should answer are listed below.

- Has the project achieved the objectives?

- What is the impact of the project on the life of beneficiaries or the community?

Indicators to assess project outcomes may include data that will show if the project has provided services to beneficiaries; have these services been appropriate to the needs of beneficiaries and consistent with the project objectives; what immediate effects did the project have on the beneficiaries or the community; are there prolonged effects on their lives; are there unforeseen effects brought about by the project? Information for such indicators can be provided by the project staff and management, beneficiaries, people who know the beneficiaries (e.g. family, teachers, peers) and community leaders. Some indicators may be based on statistical and community reports. Other indicators may use surveys and standardised quantitative data gathering. Qualitative inputs from interviews or focus groups can also be used as outcome evaluation indicators. The choice of indicators for results oriented evaluation is limited only by two aspects: creativity of the evaluator and their relevance as evidence of a relationship between the project objectives and the achieved change in the life of project beneficiaries. Therefore, such indicators are also called performance indicators.

\section{Internal logic of outcome evaluation}

The logic of outcome evaluation is rather straightforward. The assumption is that if project inputs (activities) produce outputs (which are immediate accomplishments of a project) and these outputs lead to planned outcomes (measurable or observable results), then the project will produce a desirable impact on the lives of individuals, the community, institutions or systems which are reflected in the change of their status, behaviour or relationships.

There may be different levels of inputs and outputs in a single project. However, each level of expected results is linked in causeeffect relationships to the previous level of inputs. Results of a previous level are considered inputs for the next level of outputs.

Let us look at the following example. A community based psychosocial project is set up with a goal to provide emotional, psychological and organisational support to families who have lost members in a natural disaster, and to set up a community counselling centre that will serve these needs for the next two years. The location is a rural area with very limited professional resources, thus requiring a project that will address needs of the community, families and individuals. The project envisions activities at several levels, one being a prerequisite for the next one.

The activities (inputs) at the first level could include: (1) capacity building of local volunteer care providers in mastering helping skills that will serve to strengthen the resources of the victimised families; (2) disseminating information about typical post traumatic reactions and coping with losses; and (3) providing limited professional counselling to the highly traumatised individual by a mobile professional team from outside of the community. The assumption is that if these activities are well delivered and meet the beneficiaries' needs (i.e. the activities/ outputs relationships hold true), then the outputs should be achievable.

The outputs at this level could be: (1) trained care providers, willing and able to provide organised assistance; (2) improved social 
and work functioning of highly traumatised individuals; and (3) better understanding of the relationship between traumatic loss in the community and people's behaviour and emotional turmoil. The assumption here is that some outputs are beneficial for the individuals (i.e. improved social and work functioning of the traumatised individuals) while some outputs are only a precondition for activities at further levels (i.e. trained volunteers).

In this way, first level outputs serve as inputs for the second level outputs. The assumption is that if the achieved outcomes at the first level are really working (i.e. trained volunteers, population aware of relationship between traumatic exposure and post traumatic reactions), then the community counselling centre can be set up and staffed with the trained volunteer care providers; the traumatised and other distressed individuals and families will access the support in the years to come; seeking assistance for mental health problems would not be stigmatising; etc. In turn, if these outcomes are achieved as expected, then the project should contribute to the stated goal and should have the desired impact on the life of the whole community, affected families and individuals.

At this time a word of caution should be made: psychosocial and community based projects are not implemented in a controlled environment. There are a number of external factors that can influence the project implementation and achievement of the planned goal. Most of these events are a threat to the project success, but sometime external events can facilitate the project implementation. In any case, such events need to be accounted for as much as possible in the project planning phase. However, whether a threat or beneficial, not knowing about such events risks a good summation evaluation because this can compromise the assumptions about the causal relationship between inputs, outputs and expected outcomes.

As illustrated previously, outcome evaluation is based on a set of assumptions describing the necessary conditions that must exist if the cause-effect relationship between inputs and different levels of results are to occur as expected. In the previous example, after being trained, the care providers may not be willing to staff the community counselling centre as volunteers, but require compensation that is unavailable. This is an external threat to the project achievement that should have been accounted for in the project planning phase and as the contingency plan developed. The risk is external to the relations of inputs and outputs, but seriously affects the achievement of project goal and its impact. Therefore, it cannot be ignored in the outcomeevaluation and must be addressed. On the other hand, another sort of external event might be that the community authorities decide to pay for the services of the newly trained providers. This is an external event beneficial for the project goal, but not necessarily a direct outcome of the project inputs. We would agree that this was a spin-off effect of the impact of the project on the community that was beyond expectations. For example, if two family members of the mayor completed the training, and they got a job at the counselling centre, such an external factor could not be easily connected to the project outcome. Therefore, without knowing the motivation for this decision, it should be considered a risk for the outcome evaluation.

The risks for project implementation need to be considered when planning the project. In turn, during the outcome evaluation considering whether these risks have been well accounted for, will help better understand the possible under achievements of objectives (as well as unexpected achievements) and help formulate the recommendations and 
decisions about the future of the project. So, assumptions upon which the project design is based serve for risk analysis, developing contingency plans, and for the summation evaluation.

\section{Development of performance evaluation indicators}

Performance indicators are qualitative or quantitative measures used to document progress made toward the achievement of outputs, outcomes and project impact. Their specific form and contents will depend on the specifics of the project, but project stakeholders should agree, in the initial stages, which performance indicators will be used as evidence of project outcomes and impact.

Based on evaluation methodology and empirical criteria for developing good performance indicators, the indicators that could be included are listed below.

1. Validity: Does the indicator document the intended result? Is it clearly related to the conditions the project seeks to change (e.g. training care providers is not a good indicator of the number of children who will receive improved trauma support - the trained care providers may not be practicing this service)?

2. Reliability: Does it provide consistent information over time, even if the outcomes stay the same?

3. Sensitivity: Can it detect changes in the outcomes even if they are relatively small?

4. Simplicity: Is it easy to collect and analyse the data? Does it require specific training in data collection and analysis?

5. Affordability: Can the project afford to collect the data needed for the indicator?
Can it be available at a reasonable cost using an appropriate collection method?

6. Relevance: Will the information be useful for decision making and learning? Can it provide information needed for different stakeholders (field staff may need different indicators than donors or community leaders)?

7. Timely: Can data be collected and indicators reported at the right time to be used for decision making?

8. Measurable: Quantifiable indicators are preferred because they can be aggregated; they are easily presented and enable comparisons; however, qualitative indicators should be used where justifiable. $^{1}$

Indicators showing an output after a project activity may be rather simple, but they are more complex at the higher project levels, i.e. at the outcome and impact levels. This is when expertise, experience and creativity come in and when an agreement among different stakeholders is important.

For each output there might be several performance indicators, but using too many of them is not efficient. Usually not more than three indicators are used per output and outcome. Which ones to use can be decided after scrutiny for possible indicators applying the eight criteria listed above.

Qualitative performance indicators are a preferred choice under certain conditions, when there is an advantage over the standardised quantitative measures. This is especially true under circumstances (Patton, 1990) listed below.

- Individualised outcomes can be expected for different beneficiaries or groups. 
- The internal dynamics (process of change) of the intervention is of particular interest.

- The standardised data collection can interfere with the project objectives.

- Data collection should be personalised (e.g. because of high vulnerability of beneficiaries; sensitive or very private information).

- If good standardised instruments are not available.

- Qualitative approach is more cost effective and serves the stakeholders' needs.

\section{Examples of indicators from evaluated projects}

The Society for Psychological Assistance (SPA), a non-governmental organisation with extensive experience in providing community based psychosocial programs, consultancy, supervision and evaluation based in Croatia, over the past several years has been increasingly commissioned as an independent evaluator. The following are examples from some of the evaluated projects, illustrating the variety of performance indicators that have been developed specifically for each case.

Case 1. Project: Building a democratic society based on a culture of nonviolence: peace building in eastern Croatia. During the 1991-1995 war that followed the break-up of Yugoslavia and in the aftermath of the war, a number of non governmental organisations (NGOs) have provided psychosocial projects aimed at helping the recovery of the affected people. A regional NGO with the mission of promoting nonviolence and peace provided a three year project in several areas of Croatia that had been most affected by the war. The project objectives were to help alleviate the emotional suffering of families that suffered losses, promote interethnic relations and the building of the civil society.

Main project activities:

- Recruitment and training of peace teams

- Providing psychosocial support to war affected populations through active listening

- Assessment of local needs and feasibility of community actions

- Contacts with local authorities and the media

- Implementation of community joint actions and empowerment of citizens for such actions by training them, supporting their actions and networking

Evaluation objective:

- To assess the effects of the peace building project on the communities in which it has been implemented

Method:

- Qualitative; 17 focus groups including various community representatives and stakeholders, different ethnic groups; five locations

\section{Performance indicators:}

- Recruited and trained over 30 peace teams who practiced active listening with hundreds of families - output

- Perception of the peace teams and their work by the community members outcome

- Empowerment of specific groups for community actions: women, youth and Roma engaged in joint actions - outcome

- Relationship between different ethnic groups in a community - community outcome 
- Improved feelings of safety in communities - community impact

- Development of the civil society (new NGOs founded and working) - community impact

- Relationship between NGOs, and collaboration between NGOs and local authorities - community impact

Case 2. Project: Psychosocial training for teachers in Kosovo (Training of Trainers). After the war in Kosovo (1999) a leading international NGO started a major project aimed at alleviating the effects of trauma and massive loss in the population. The project included; setting up of medical and counselling centres, providing medication, distribution of food and materials for rebuilding homes and institutions. One specific segment of the project focused on reaching the traumatised population through the school system. This part of the overall project, evaluated by SPA, dealt with the capacity building of the school staff to become more competent helpers to children and their parents affected by the war in about 30 local communities in Kosovo. The project activities included training of over 140 teachers and school principals for 6 days in communication and helping skills, basic of psychological effects of trauma a loss and empowerment of children and their families.

Project objectives:

- Increase the knowledge and competence in dealing with trauma and post traumatic reactions of health and education professionals that will serve as local trainers

- Increase the professional capacity of primary school teachers to deal with war related trauma in children within the school context
Evaluation objectives:

- Assess the change in new and specific knowledge among the local trainers and teachers related to trauma and assistance in post trauma problems within the school context

- Assess the feeling of professional competence in working with children affected by the war

- Assess the understanding of the specific needs of children and families in destabilised communities

- Assess the change in the teacher's practice

\section{Method:}

- Quantitative (administration of questionnaires; pre/post design) and qualitative (interviews and focus groups with trainers and trainees; interviews with international trainers, mangers and project staff)

Performance indicators at the outcome level:

- Self assessment of specific new knowledge and skills

- Self assessment of professional development

- Assessment of knowledge: specific knowledge questionnaire

- Assessment of professional competence: professional competence questionnaire

- Assessment of new practices: specific practice items; self-report during focus groups, case presentations

The project was implemented for one year, which allowed the evaluation at the outcome level, for which the above indicators were used. For each indicator a specific assessment instrument was used that provided measurable effects. In addition, qualitative data enabled observation of the change in behaviours and status of the school staff. However, should the stakeholders have been interested in the project impact on the lives of individuals, 
families and communities, additional indicators would have to have been used.

Case 3: Project: Introduction of mediation services in a community. A regional NGO from East Croatia implemented a project aimed at introducing mediation services in three communities. These services were planned to be provided directly to the clients in resolving their disputes, and also in association with the municipal courts of law that would refer the clients to court related mediation instead of pursuing civil litigation. The project activities were multi-fold and included: training of mediators and support staff for about 12 days, training judges to become aware of benefits of court-related mediation, developing promotional materials, negotiating support from local authorities, local public promotionalcampaigns, and developing training package for training of future mediators.

Project objective:

- Introduce mediation in three communities, develop capacities and sustainable structures for mediation in a community

Evaluation objectives:

- Evaluate the project impact on introducing and functioning of a sustainable mediation service and out-of-court agreements in selected communities

Method:

- Qualitative: Focus groups with mediators at mid-project and at the project completion about practices in established mediation services

- Quantitative: analysis of service logs, documents on advocacy and promotional actions; number of clients

Performance indicators:

- Trained mediators and support staff output
- Office space provided by the local government in one of the communities - output

- Completed education package on mediation for training of new mediators - output

- Established and functioning three mediation centres, accessible to clients - outcome

- Mediators providing services in mediation centres to clients several days a week - outcome

- Number of self-referred clients; number of clients served - outcome

- Successful/unsuccessful outcomes of mediation cases - outcome

- Common knowledge about the mediation centres in the three communities - outcome

- New mediators interested in entering training and in volunteering their time impact

Because of the short time (two years) of the project implementation, the evaluation at the community or individual impact level could not be done to assess the sustainability of mediation services.

Case 4: Project: Psychosocial treatment of perpetrators of family violence. A regional NGO worked for five years to introduce psychosocial treatment of perpetrators of family violence in Croatia as a regular service to which courts and social services could refer clients for treatment. This work included training of potential professional staff, lobbying government ministries to introduce changes in the legal framework, promoting benefits of such service among the judiciary, social services, women organisations, and caring professions. This long term project will be evaluated using the framework below.

Project objective:

- To introduce psychosocial treatment of perpetrators of family violence in several major cities in Croatia 
- Evaluation objective:

- To evaluate the effects of psychosocial treatment, its integration with other community services and its sustainability

Method:

- Quantitative: number of clients; analysis of service logs

Performance indicators:

- Established, licensed and staffed five treatment centres - output

- Number of clients entering into the treatment - output

- At least $80 \%$ of clients completing the treatment - outcome

- At least $75 \%$ of those who completed demonstrate increased anger control and change of expressed attitudes towards women at sessions - outcome

- At least $80 \%$ of those who completed declare awareness that they are responsible for own violent behaviour - outcome

- At least $60 \%$ of families were free from physical violence in next 12 months (documented by not being reported by the police) - outcome

- Social services, courts and prosecutors refer clients to treatment at an increasing rate within a 12 months time frame impact

- Local and state authorities provide funding for the treatment - impact

\section{Conclusion}

Evaluation is a highly creative process of searching for answers that the different stake- holders of a psychosocial project need. It has to bring together the need to have valid answers about the relationship between the inputs and the outcomes of a project, and the realistic constraints of providing these answers within the conditions of uncontrollable environment in which projects are implemented. Development of evaluation indicators is one of the crucial steps in the evaluation that requires knowledge, experience, critical thinking, and ability to adhere to the internal evaluation logics and scrutinise each of them against a set of criteria.

\section{References}

Ajdukovic, D. (1995). Stoje psihosocijalna pomoc? /What is psychosocial assistaence?/ In: Ajduković D. (ed.) Programi psihosocijalne pomoci prognanoj $i$ izbjegloj djeci /Programs of psychosocial assistance to refugee and displaced children. Zagreb: Society for Psychological Assistance and UNICEF, 5- 15.

Patton, M. Q. (1990). How to use qualitative methods in evaluation. Newbury Park, CA: Sage.

${ }^{1}$ Readers may be familiar with the SMARTacronym that stands for Specific, Measurable, Appropriate, Realistic, Timebound. Obviously there is an overlap with the more elaborate list of criteria for performance indicators provided in this article.

Dean Ajdukovic is attached to the Department of Psychologyatthe University of Zagreb-Croatia. email:dean.ajdukovic@ffzg.hr 